Disponível em

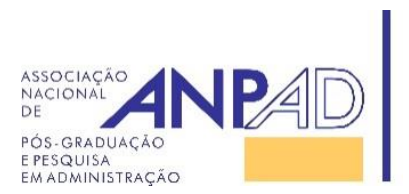

http://www.anpad.org.br/rac

RAC, Rio de Janeiro, v. 20, n. 4, art. 1, pp. 389-411, Jul./Ago. 2016

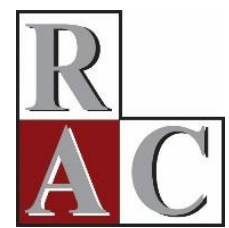

\title{
A Influência do Poder no Relacionamento entre Consumidor e Marca
}

The Influence of Power in the Relationship between Consumers and Brand

Elder Semprebon ${ }^{1}$

Paulo Henrique Muller Prado ${ }^{1}$

Universidade Federal do Paraná ${ }^{1}$

Artigo recebido em 28.11.2014. Última versão recebida em 15.09.2015. Aprovado em 20.09.2015. Publicado online em 11.03.2016. 


\title{
Resumo
}

Pertencente à área de pesquisas sobre relacionamento entre consumidor e marca, o objetivo deste estudo é verificar a influência do poder da marca sobre o senso de poder do consumidor e os papéis da dependência e confiança como variáveis de mediação e moderação, respectivamente, nesta relação. A primeira hipótese defende que, na presença de marcas com alto poder, os consumidores sentirão baixo poder pessoal. Para compreender melhor este fenômeno, a dependência surge como uma variável mediadora, já que a quantidade de poder se refere ao nível de dependência entre as partes, ou seja, marcas com alto poder geram maior dependência e, desta forma, reduzem o senso de poder pessoal do consumidor, aumentando a assimetria de poder, sendo esta afirmação a segunda hipótese do estudo. Por último, constatou-se que a confiança é uma variável importante na redução de assimetria de poder; portanto, em níveis de alta confiança, o efeito negativo do poder da marca, mediado pela dependência, sobre o poder pessoal, é menos intenso, sendo este argumento a terceira hipótese do estudo. Foram realizados três experimentos que possibilitaram a corroboração de todas as hipóteses. Esta pesquisa traz um significativo avanço no entendimento das relações entre consumidor e marca ao propor um novo modelo baseado na perspectiva de poder.

Palavras-chave: marca; poder; dependência; confiança.

\begin{abstract}
Belonging to the area of research concerning the relationship between consumers and brands, the objective of this study is to investigate the influence of brand power on consumers' sense of power and the roles of dependency and trust as mediating and moderating variables, respectively, in this relationship. The first hypothesis states that in the presence of brands with high power, consumers will have the perception of low personal power. For a better understanding of this phenomenon, dependence emerges as a mediating variable. The amount of power refers to the degree of dependence between the parties; i.e., brands with high power generate greater dependence and therefore reduce the sense of personal power by the consumer, which increases the asymmetry of power, this statement is the second hypothesis of the study. Finally, research found that trust is an important variable in reducing asymmetry of power. This finding shows that high levels of confidence in the negative effect of brand power, mediated by dependence on personal power, is less intense compared to a low-trust condition. Three experiments were performed that confirm the proposed hypotheses. This research brings a significant advance in understanding the relationship between consumers and brands, and proposes a new model based on the power approach.
\end{abstract}

Key words: brand; power; dependence; trust. 


\section{Introdução}

O presente trabalho pertence à área de estudos sobre o relacionamento entre consumidor e marca. Tais pesquisas apoiam-se no pressuposto que consumidores podem criar ligações afetivas com objetos de consumo, incluindo marcas (Thomson, Maclnnis, \& Park, 2005), e que sujeitos podem formar relacionamentos com marcas da mesma maneira como se relacionam com outros indivíduos, sendo estes relacionamentos válidos ao nível de experiências vivenciadas (Fournier, 1998).

A área de estudos sobre relacionamentos entre consumidor e marca possui uma abundante literatura. Os principais construtos estudados são brand personality, brand love, brand attachment, brand relationship quality, brand satisfaction, brand trust, brand commitment, brand loyalty e brand engagement. Embora o poder tenha um papel fundamental nos relacionamentos, é um construto ainda não explorado neste contexto.

Estudos de poder no campo do comportamento do consumidor são raros. Aqueles encontrados dizem respeito ao consumo compensatório de indivíduos com baixo poder (Rucker \& Galinsky, 2008), escolha dos gastos (Rucker, Dubois, \& Galinsky, 2011), comportamento de troca de produtos e marcas - sobretudo para consumidores com alto poder (Jiang, Zhang, \& Rucker, 2014), percepção de preço injusto em relação a compras anteriores (baixo poder) e compras de outras pessoas (alto poder) (Jin, He, $\&$ Zhang, 2014). Tradicionalmente em marketing, o tema poder tem sido mais estudado na área de varejo e canais (Ailawadi, 2001; Burt \& Sparks, 2003; Fuchs \& Kalfagianni, 2009; Inderst \& Shaffer, 2007; Kumar, Scheer, \& Steenkamp, 1995; Rindt \& Mouzas, 2015; Skinner, Dubinsky, \& Donnelly, 1984; Yani-de-Soriano \& Foxall, 2006).

Em uma citação clássica, Russel (1938) afirma que o poder é um conceito fundamental nas ciências sociais, da mesma maneira que a energia é um tópico primordial para a física. Poder é uma das características mais fundamentais do mundo social (Malkoc, 2012). Ele não opera em uma esfera específica da vida social, mas ocorre no dia a dia. Tem um papel direto e criativo na sociedade (Friedmann, 1992). É um rico construto no que diz respeito à tradição teórica multidisciplinar presente em estudos sobre comportamento (Fournier \& Alvarez, 2013). É talvez o fenômeno social humano mais universal. As consequências do poder são vivenciadas em todos os níveis sociais (Grimes, 1978).

De forma geral, poder é uma parte integral de qualquer relacionamento, pois determina como os parceiros se relacionam e como as decisões são tomadas (Dunbar, 2000). Assim, torna-se fundamental a explicação das relações de poder entre consumidores e marcas.

O poder da marca vem sendo discutido nos últimos anos como um importante tema na área de marketing. Pode ser definido como a habilidade de uma marca em influenciar o comportamento do consumidor e levar uma pessoa a realizar algo que caso contrário não faria (Crosno, Freling, \& Skinner, 2009). Não há estudos que mostrem como o poder da marca influencia o senso de poder pessoal do consumidor, que é definido como a habilidade de controlar recursos, próprios ou de outros, sem interferência social (Galinsky, Gruenfeld, \& Magee, 2003). Assim, o objetivo deste estudo é verificar a relação de poder entre consumidor e marca.

Toda relação social, no que se refere ao poder, é fundamentalmente diádica e assimétrica (Keltner, Van Kleef, Chen, \& Kraus, 2008; Rollins \& Bahr, 1976), sendo a dominância de uma parte baseada na oferta de recursos relevantes e na sua exclusividade como parceiro frente a demais alternativas (Emerson, 1962). Neste sentido, pode-se hipotetizar que consumidores sentirão menos poder em uma relação com marcas com alto poder.

O poder reside implicitamente na dependência do outro (Emerson, 1962). A dependência de um sujeito é uma fonte potencial de poder para outro. O desequilíbrio de poder pode ser definido pela diferença de poder causado pela dependência (Molm, 1991). A dependência percebida pelo consumidor em relação à marca tem um efeito negativo no poder pessoal, em outras palavras, a dependência 
contribui para a diminuição do senso de poder pessoal do consumidor no relacionamento com a marca, sendo, assim, um mecanismo claro de aumento da assimetria de poder entre consumidor e marca.

Contrariamente, a confiança é um importante fenômeno que contribui para a força de relacionamentos, pois possui um papel fundamental de redução da interação assimétrica de poder. Em condições de alta confiança, a percepção de desigualdade de poder entre consumidor e marca será atenuado.

A abordagem quantitativa experimental foi empregada neste estudo que pretende analisar relações causais envolvendo as variáveis poder, dependência e confiança. Assim, foram realizados três experimentos para verificação das hipóteses.

Este estudo traz diversas contribuições para o melhor entendimento das relações entre consumidor e marca, ao dar uma explicação sobre o efeito decorrente da influência do poder da marca sobre o senso de poder do consumidor e os mecanismos presentes nesta relação. Diante do exposto, o objetivo geral deste estudo é verificar a influência do poder da marca sobre o senso de poder do consumidor e os papéis da dependência e confiança como variáveis de mediação e moderação, respectivamente, nesta relação.

\section{Referencial Teórico}

\section{Poder}

Poder é, inerentemente, um construto social. Toda relação humana, não somente aquela no ambiente de trabalho ou em domínio político, é afetada por diferenças hierárquicas entre indivíduos. Poder é parte fundamental da vida social diária e um método primário de organização das relações sociais (Smith \& Galinsky, 2010). É uma força que atinge todas as interações sociais. Forma os valores do consumidor em uma variedade de decisões de consumo (Jiang, Zhang, \& Rucker, 2012).

A definição de poder divide os estudiosos. Um primeiro grupo descreve poder como a habilidade de fazer e obter o que se quer, sem estar sendo influenciado por outros. Neste caso, poder é a habilidade de ignorar a influência de outros, para controlar os próprios resultados e ser pessoalmente independente. Este tipo de poder é chamado de poder pessoal (Lammers, Stoker, \& Stapel, 2009). Um segundo grupo de estudiosos define poder como a habilidade de uma pessoa influenciar outras de modo que elas façam coisas que normalmente não fariam. Neste caso, poder significa exercer controle sobre outras pessoas. Este tipo de poder é chamado de poder social (Fiske \& Berdahl, 2007; French, 1956; Lammers et al., 2009). Simplificando, o poder social é a habilidade do indivíduo em exercer controle sobre os outros. Por outro lado, poder pessoal é a habilidade de controlar os próprios resultados sem ser influenciado por outros (Malkoc \& Duguid, 2012).

O termo poder da marca tem sido registrado em numerosas publicações gerenciais de marketing (Hanzaee, Ghalandari, \& Norouzi, 2011). Porém, o uso do termo é indiscriminado e a partir do trabalho de Crosno, Freling e Skinner (2009) é que se tem uma definição aprofundada do construto poder social da marca.

Embora uma marca não possua, de fato, poder, os consumidores que a conhecem e a usam podem atribuir autoridade, controle, influência e outras características que se baseiam no relacionamento e experiências com ela. É um componente que norteia o relacionamento entre consumidor e marca. Assim, pode-se definir o poder da marca como habilidade de uma marca em influenciar o comportamento de consumidores e levar um consumidor a realizar algo que caso contrário não faria (Crosno et al., 2009).

A visão estabelecida por Belk (1988) mostra que um consumidor é capaz de se relacionar com objetos inanimados, atribuindo a eles traços de personalidade. As pessoas podem realizar ligações afetivas e emocionais com animais, pessoas, lugares, com o lar, coleções, marcas, etc. (Thomson et al., 2005). Nesta linha, Fournier (1998) sugere que consumidores podem formar relacionamentos com 
marcas da mesma forma como se relacionam com outros indivíduos e a natureza destes relacionamentos difere de indivíduo para indivíduo.

A magnitude do poder no relacionamento pode ser evidente apenas quando há uma relação de forças de poder contrárias (Dunbar, 2000). As relações de poder são assimétricas em razão de que muitas situações de poder são caracterizadas por influência recíproca de acordo com diferentes escopos dados pelo contexto (Baldwin, 1978; Friedmann, 1992; McDonald, 1980). Não se pode esperar encontrar uma lógica estável no poder ou a possibilidade de equilíbrio entre duas partes que buscam poder. A falta de equidade existe na diferença referente à habilidade das pessoas em acessarem recursos, o que cria um desequilíbrio na esfera de poder (Friedmann, 1992). A falta de poder do consumidor pode ser definida como a crença de que este é incapaz de influenciar os resultados de um relacionamento com uma empresa (Bunker \& Ball, 2009).

O desequilíbrio de poder é inevitável nos relacionamentos. Sempre haverá uma parte dominante (alto nível de poder) e outra submissa (baixo nível de poder), ou seja, relações são assimétricas no que diz respeito à concentração de poder dada a sua natureza causal. Sujeitos que detém maior poder na relação possuem vantagens em relação a recursos, controle e dominância sobre o parceiro na situação. Como exposto, pode-se inferir que, mesmo em relacionamentos entre consumidores e marca, haverá uma relação de poder assimétrica, como exposto na H1.

H1: O senso de poder pessoal será menor ( $v s$. maior) no relacionamento com marcas de alto ( $v s$. baixo) poder.

\section{Dependência}

O poder raramente está nas mãos de uma única pessoa, mas é compartilhado quando os indivíduos se tornam mutuamente dependentes (Lawler, 1992). A dependência é considerada por muitos pesquisadores como um conceito central para explicar relacionamentos e trocas (Andaleeb, 1995). Podese definir dependência de acordo com a extensão em que os resultados de um indivíduo são contingentes com o processo de troca com outro indivíduo. A dependência é uma função de valor e de alternativas, pois na medida em que as pessoas são mais dependentes das trocas, elas valorizam mais o relacionamento, especialmente quando há poucas alternativas (Molm \& Cook, 1995). O poder, então, é alcançado diadicamente quando uma pessoa é valorizada como um parceiro de trocas, havendo poucas alternativas de substituição (Thibaut \& Kelley, 1959).

O poder de controlar ou influenciar o outro reside no controle de coisas que a outra parte valoriza, ou seja, o poder reside implicitamente na dependência do outro (Emerson, 1962). O desequilíbrio de poder nos relacionamentos advém da assimetria na dependência entre as partes, o que contribui para a diferença de influência (Casciaro \& Piskorski, 2005; Molm, 1991; Wolfe \& McGinn, 2005).

Relacionamentos baseiam-se em propriedades de poder e dependência. Desta forma, o nível de poder é proporcional ao grau de dependência atribuído ao parceiro. O desequilíbrio de poder nos relacionamentos advém da assimetria na dependência entre as partes, o que contribui para a diferença de influência. A dependência é gerada pela capacidade de a parte dominante fornecer recursos relevantes para se tornar um parceiro exclusivo, evitando buscas alternativas pela parte submissa.

H2: O efeito indireto do poder da marca, através da dependência, sobre o poder pessoal, será negativo.

\section{Confiança}

A confiança é normalmente baseada na expectativa individual sobre como outra pessoa irá se comportar em ocasiões futuras. É vista como resultado de um processo, sendo que a confiança em um relacionamento se desenvolve gradualmente (Blomqvist, 1997). Chaudhuri e Holbrook (2001) definem confiança na marca como a disposição dos consumidores em acreditar na capacidade de a marca realizar 
a função declarada. A confiança reduz a incerteza em uma situação em que o consumidor se sente especialmente vulnerável, pois ele sabe que pode contar com a marca em que confia.

Para Rousseau, Sitkin, Burt e Camerer (1998), a confiança possui um importante papel moderador nas relações teóricas em que prevalece condições de causalidade entre construtos, principalmente nos estudos sobre comportamentos interpessoais.

Confiança e dependência são qualidades elementares nos relacionamentos, embora tais variáveis não tenham sido suficientemente relacionadas na teoria. Níveis de confiança são necessários para o desenvolvimento de repetidas transações e à medida em que um relacionamento se desenvolve, a dependência entre os parceiros aumenta (Laaksonen, Pajunen, \& Kulmala, 2008). Segundo Andaleeb (1995), seria questionável afirmar que confiança e dependência são a mesma coisa. Para o autor, é possível para uma parte dependente não confiar na outra parte. Assim, em determinadas circunstâncias, o grau de confiança entre os parceiros pode moderar o efeito da dependência.

Singh e Sirdeshmukh (2000) expõem claramente que os estados de confiança e falta de confiança são qualitativamente diferentes em termos de valência (positiva e negativa) e têm um potencial impacto sobre a igualdade ou assimetria da relação. Segundo Olekalns e Smith (2006), o alto nível de confiança aumenta a consciência para a entrada em relações justas, permitindo trocas mais igualitárias de recursos, incluindo informações. Algumas díades possuem igualdade de poder, outras, desigualdade. A principal expectativa é que o nível de confiança seja mais alto em grupos onde a díade tenha simetria de poder do que quando há assimetria de poder. Com extrema disparidade de poder, é difícil alcançar a confiança. Isto significa que os atores em díades com baixa ou moderada assimetria de poder podem confiar mutuamente mais do que pares em relações de poder consideradas desiguais (Öberg \& Svensson, 2010). O estudo de Cai, Goh, Souza e Li (2013) demonstrou que o impacto do poder era reduzido quando havia confiança na relação entre duas partes.

H3: A confiança irá moderar o efeito indireto (dependência) do poder da marca sobre o poder pessoal. Especificamente, em condições de alta ( $v s$. baixa) confiança, o efeito indireto negativo (dependência) do poder da marca sobre o poder pessoal será menor ( $v s$. maior).

\section{Metodologia}

A partir das hipóteses, foi possível elaborar o modelo de pesquisa, que demonstra graficamente a direção das relações hipotéticas envolvendo as variáveis estudadas, conforme Figura 1.

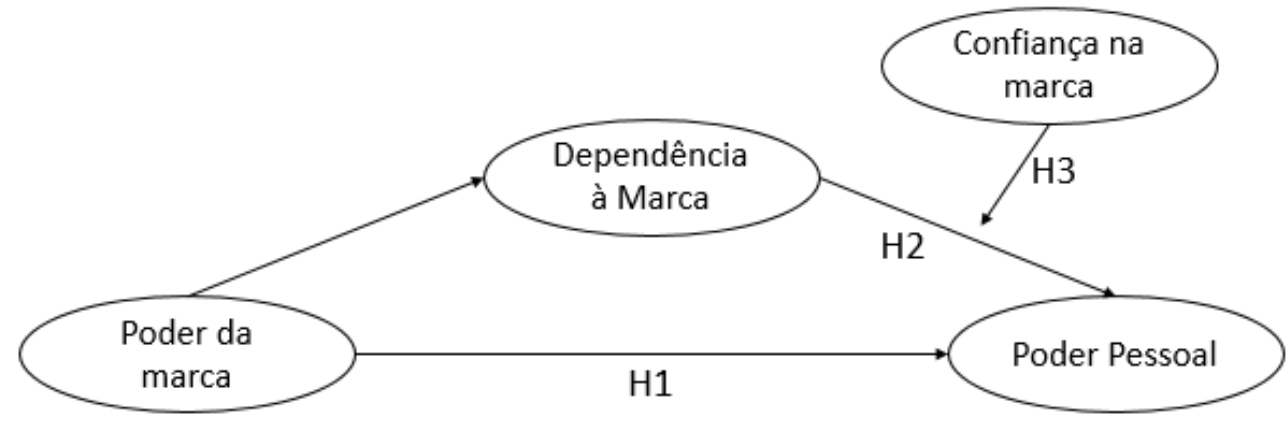

Figura 1. Modelo de Pesquisa

Fonte: elaborada pelos autores.

Com o objetivo de se determinar a influência do poder no relacionamento dos consumidores com marcas, faz-se a opção metodológica pela abordagem quantitativa experimental. Para Shadish, Cook e Campbell (2002), o experimento é o tipo de pesquisa melhor ajustado para o estudo de relações causais. As hipóteses foram testadas em três experimentos. 
Em relação ao desenho dos experimentos, emprega-se o tipo entre grupos (between-subjects design), no qual cada grupo participante recebe apenas um estímulo de maneira isolada aos demais. Assim, caracteriza-se como entre grupos já que o contraste é realizado entre os grupos manipulados (Goodwin, 2007; Shadish, Cook, \& Campbell, 2002).

Algumas variáveis do modelo foram experimentalmente manipuladas (poder da marca e confiança), conforme descrito adiante. Outras variáveis (dependência e poder pessoal), inclusive a checagem do poder da marca e da confiança, classificam-se, segundo Hair, Anderson, Tatham e Black (2005) e Lattin, Carroll e Green (2011), como latentes, que não podem ser diretamente medidas, mas podem ser representadas por um ou mais indicadores. Ainda segundo os autores, esse procedimento tem justificativa tanto prática quanto teórica, devido à melhoria da estimação estatística, melhor representando conceitos teóricos, bem como devido à explicação do erro de mensuração. O modelo de pesquisa é composto por indicadores reflexivos, ou seja, os indicadores são manifestações dos construtos (Jarvis, Mackenzie, \& Podsakoff, 2003). Esta característica permite que se utilize modelos de agregação parcial pela média dos indicadores (Hair, Anderson, Tatham, \& Black, 2005; J. C. Anderson \& Gerbing, 1988). A principal vantagem deste procedimento é a de se reduzir o número de parâmetros a serem estimados e, ao mesmo tempo, diminuir os erros de mensuração. Para esta agregação parcial, os indicadores a serem combinados devem ser unidimensionais e estarem ligados de forma consistente ao construto ao qual são representativos (Bagozzi \& Edwards, 1998).

Foram utilizadas as escalas de poder da marca (Crosno et al., 2009), senso de poder pessoal (C. Anderson, John, \& Keltner, 2012) e confiança (Francisco-Maffezzolli, Semprebon, \& Prado, 2014). Os itens para mensurar a dependência em relação à marca foram extraídos da literatura devido à ausência de uma escala adequada para esta pesquisa, sendo: A marca é importante para mim, Sinto-me dependente da marca e A marca contribui na realização das minhas tarefas. Todas os itens foram mensurados em escala de concordância com 10 pontos (1-Discordo totalmente/ 10-Concordo totalmente).

As amostras são compostas por estudantes universitários de diversos cursos e instituições de ensino (experimentos 1 e 3) e praticantes de corrida de rua (experimento 2) escolhidos aleatoriamente, respectivamente, em sala de aula e comunidades virtuais. Quanto ao tamanho amostral, o número mínimo de participantes em cada condição foi de 30 estudantes ou corredores de rua, atendendo a condições para o uso de testes estatísticos paramétricos.

Afim de eliminar o possível viés nas respostas dos participantes (common method bias), observouse alguns cuidados sugeridos por Podsakoff, MacKenzie, Lee e Podsakoff (2003) na aplicação dos questionários, ao evitar que os respondentes tenham participado de qualquer pesquisa recente com variáveis semelhantes e ao utilizar, no questionário, indicadores e variáveis de diferentes fontes. Além disso, analisou-se também a percepção e a relação dos participantes com a marca, a importância do produto, a dificuldade para responder e o envolvimento com a pesquisa. Na apresentação dos resultados de cada experimento, serão demonstrados em detalhes os procedimentos de coleta e análise dos dados.

\section{Resultados}

\section{Experimento 1}

O primeiro experimento do estudo teve como objetivo testar o efeito principal da variável poder da marca sobre o senso de poder pessoal do consumidor, avaliando, assim, a H1.

A amostra foi composta por 180 respondentes, sendo distribuídos aleatoriamente entre as duas condições (poder da marca: alto e baixo) entre grupos (between subjects). Na condição alto poder da marca, o grupo era composto por 93 indivíduos, e a condição baixo poder da marca continha 87 participantes. Todos os respondentes eram universitários, sendo 55,6\% do sexo masculino. A média de 
idade foi 22,16 anos (D.P.: 4,57). A aplicação do questionário em papel se deu de forma presencial em salas de aula de duas universidades (pública e privada) nos cursos de graduação em administração e marketing.

Em um dos cenários, foram apresentadas as características de uma marca fictícia de tênis com baixo poder e, em outro, uma marca fictícia de tênis com alto poder. A descrição das marcas seguiu as determinações de Crosno et al. (2009) sobre as propriedades de marcas com alto e baixo poder.

Tabela 1

\section{Cenários da Marca (Exp.1)}

\begin{tabular}{ll}
\hline Marca com baixo poder & Marca com alto poder \\
\hline Você acaba de adquirir um tênis da marca XYZ. A & Você acaba de adquirir um tênis da marca XYZ. A \\
marca de tênis XYZ não é considerada famosa. & $\begin{array}{l}\text { marca de tênis XYZ é famosa entre jovens e adultos } \\
\text { do mundo todo. Muitas pessoas afirmam que há uma }\end{array}$ \\
Geralmente as pessoas que usam a marca de tênis & grande similaridade entre elas e a marca XYZ. Os \\
XYZ não costumam comentar nada de especial sobre a & valores divulgados pela marca estão alinhados com \\
marca. A marca XYZ não emite qualquer tipo de valor & vales \\
para seus compradores. A XYZ é uma marca de tênis & aqueles em que seus amigos também acreditam, por \\
com qualidade. & $\begin{array}{l}\text { isso eles compram tênis da XYZ. A XYZ é uma marca } \\
\text { de qualidade e oferece benefícios interessantes. Assim, } \\
\text { muitos se sentem atraídos e identificados com a marca }\end{array}$ \\
& $\begin{array}{l}\text { XYZ. Muitas pessoas associam-se a XYZ, buscando } \\
\text { informações sobre ela e participando de eventos }\end{array}$ \\
promovidos pela marca. Você já ouviu um amigo seu \\
dizendo que gosta da marca e que ele se sente similar a \\
ela.
\end{tabular}

Nota. Fonte: elaborada pelos autores.

A seguir, apresenta-se os resultados da checagem dos cenários do experimento 1 (Tabela 2):

Tabela 2

\section{Checagens do Experimento 1}

\begin{tabular}{|c|c|c|c|c|c|c|}
\hline Variável & Cenário & Média & D.P. & t-value & Sig & Alpha \\
\hline \multirow[t]{2}{*}{ Importância do uso de tênis } & Baixo poder da marca & 7,34 & 2,096 & $-0,625$ & 0,535 & \\
\hline & Alto poder da marca & 7,53 & 0,188 & & & \\
\hline \multirow[t]{2}{*}{ Realismo do cenário } & Baixo poder da marca & 6,55 & 1,98 & $-1,652$ & 0,100 & \\
\hline & Alto poder da marca & 7,06 & 2,17 & & & \\
\hline \multirow[t]{2}{*}{ Dificuldade para responder } & Baixo poder da marca & 2,94 & 2,16 & $-0,749$ & 0,455 & \\
\hline & Alto poder da marca & 3,18 & 2,14 & & & \\
\hline \multirow[t]{2}{*}{ Envolvimento com a pesquisa } & Baixo poder da marca & 7,93 & 1,98 & $-1,392$ & 0,166 & \\
\hline & Alto poder da marca & 8,29 & 1,46 & & & \\
\hline \multirow[t]{2}{*}{ Poder da marca } & Baixo poder da marca & 5,08 & 1,50 & $-3,416$ & 0,001 & 0,892 \\
\hline & Alto poder da marca & 5,93 & 1,81 & & & \\
\hline
\end{tabular}

Nota. Fonte: elaborada pelos autores. 
Conforme Tabela 2, verifica-se que não houve diferença significativa entre as variáveis e que há relevante importância no uso do tênis, considerável realismo do cenário, baixa dificuldade para responder à pesquisa e alto envolvimento dos participantes, corroborando a validade interna do experimento. Confirma-se também a eficácia das manipulações do poder da marca, já que a percepção de poder da marca foi maior para o cenário de alto poder da marca. Por último, comparou-se a média do senso de poder pessoal em cada condição do experimento para o teste de H1 (Figura 2).

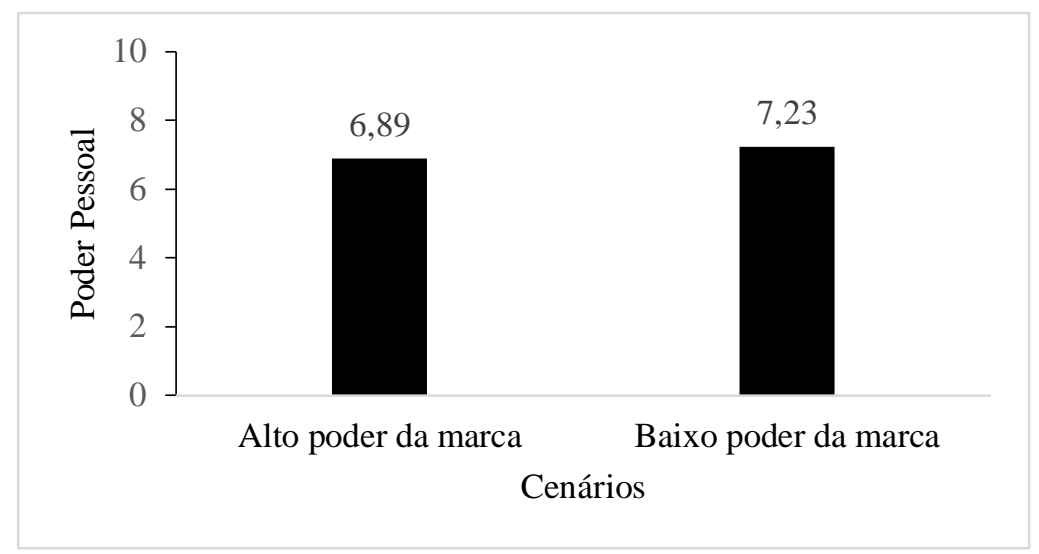

Figura 2. Média do Poder Pessoal por Cenário de Marca (Exp. 1)

t-value: 2,464; Sig=0,015; Alpha de Cronbach: 0,63. Fonte: elaborada pelos autores.

Conforme Tabela 1, na presença de uma marca com baixo poder, o poder pessoal do consumidor será maior do que na condição de alto poder da marca. Os resultados do experimento 1 corroboram a primeira hipótese da pesquisa, que afirma que o poder pessoal será menor na relação com marcas de alto poder. Estes resultados comprovam que em relações entre consumidor e marca há assimetria de poder. Quando uma das partes tem mais poder, a outra, respectivamente, tem menos poder.

Este achado reforça os argumentos teóricos já apresentados por outros autores, que afirmam que o desequilíbrio de poder é evidente na maioria dos relacionamentos (Wolfe \& Mcginn, 2005), e as relações de poder são móveis, não igualitárias e assimétricas (Friedmann, 1992). O poder estará mais saliente quando for assimetricamente distribuído, ou seja, quando as partes possuírem níveis diferentes de poder (Olekalns \& Smith, 2006).

\section{Experimento 2}

O segundo experimento teve como objetivo confirmar a $\mathrm{H} 1$ e testar também a H2. Para isso, além de avaliar o impacto do poder da marca sobre o poder pessoal, foi acrescentada a variável mediadora dependência em relação à marca.

A amostra do segundo experimento foi composta por 60 respondentes, sendo distribuídos igualitariamente, 30 em cada grupo, e aleatoriamente entre duas condições (poder da marca: alto e baixo), com design single factor, entre grupos (between subjects). Os participantes da pesquisa eram $72 \%$ do sexo masculino. A média de idade foi 29,55 anos (D.P.: 8,198). O experimento foi realizado via internet com a utilização de um software para pesquisas on-line. Os respondentes foram encontrados em comunidades virtuais de praticantes de corrida de rua.

Os participantes foram divididos aleatoriamente entre duas condições, de acordo com o poder da marca, sendo uma condição de análise para a marca Asics (alto poder) e, outra, para a marca Rainha (baixo poder). No início do experimento, cada indivíduo leu um cenário sobre a participação em uma corrida de rua com um dos tênis, conforme Tabela 3. 
Tabela 3

\section{Cenários da Marca (Exp.2)}

\begin{tabular}{ll}
\hline Marca com baixo poder & Marca com alto poder \\
\hline Imagine-se na seguinte situação: no próximo domingo, & Imagine-se na seguinte situação: no próximo domingo, \\
você irá participar de uma corrida de rua. Seu principal & você irá participar de uma corrida de rua. Seu principal \\
objetivo é atingir um bom desempenho. Nesta corrida, & objetivo é atingir um bom desempenho. Nesta corrida, \\
você quer alcançar um bom tempo de prova, superar & você quer alcançar um bom tempo de prova, superar \\
seus limites e, quem sabe, estar entre os primeiros a & seus limites e, quem sabe, estar entre os primeiros a \\
cruzarem a linha de chegada. Para esta prova, o tênis & cruzarem a linha de chegada. Para esta prova, o tênis \\
que você usará é da marca RAINHA. O tênis tem a & que você usará é da marca ASICS. O tênis tem a parte \\
parte superior (cabedal) em tecido de tramas abertas & superior (cabedal) em tecido de tramas abertas para \\
para maior ventilação interna. A entressola é em EVA & maior ventilação interna. A entressola é em EVA para \\
para suporte ao pé e calcanhar. O solado é em & suporte ao pé e calcanhar. O solado é em borracha, \\
borracha, para maior aderência. Descreva abaixo como & para maior aderência. Descreva abaixo como você se \\
você se sentiria usando um tênis da marca RAINHA & $\begin{array}{l}\text { sentiria usando um tênis da marca ASICS nesta } \\
\text { nesta situação. }\end{array}$ \\
\hline
\end{tabular}

Nota. Fonte: elaborada pelos autores.

A seguir, apresenta-se os resultados da checagem dos cenários do experimento 2 (Tabela 4):

Tabela 4

\section{Checagens do Experimento 2}

\begin{tabular}{lcccccc}
\hline Variável & Cenário & Média & D.P. & t-value & Sig & Alpha \\
\hline Importância da marca & Rainha & 7,57 & 2,542 & $-0,762$ & 0,449 & \\
& Asics & 8,00 & 1,80 & & & \\
\hline Importância em melhorar o desempenho & Rainha & 7,97 & 1,671 & $-0,665$ & 0,508 & \\
& Asics & 8,27 & 1,818 & & & \\
\hline Realismo do cenário & Rainha & 5,87 & 2,488 & $-2,987$ & 0,004 & \\
& Asics & 7,53 & 1,776 & & & \\
\hline Dificuldade para responder à pesquisa & Rainha & 2,17 & 1,289 & $-0,950$ & 0,346 & \\
& Asics & 2,67 & 2,578 & & & \\
\hline Envolvimento com a pesquisa & Rainha & 8,43 & 1,331 & 0,532 & 0,596 & \\
& Asics & 8,23 & 1,569 & & & \\
\hline Poder da marca & Rainha & 3,53 & 1,80 & $-9,701$ & 0,000 & 0,966 \\
& Asics & 7,61 & 1,42 & & & \\
\hline Dependência em relação à marca & Rainha & 2,79 & 1,89 & $-6,293$ & 0,000 & 0,914 \\
& Asics & 6,48 & 2,59 & & & \\
\hline
\end{tabular}

Nota. Fonte: elaborada pelos autores.

Não houve diferença de média estatisticamente significativa para os itens em relação às condições de alto e baixo poder da marca, exceto para o realismo do cenário, que pode ter sido influenciado pela falta do uso do tênis na vida real, sendo que aqueles que usam o tênis do cenário no dia a dia julgaram o cenário mais real $(M=7,28)$ do que aqueles que não usam $(M=6,31 ; t=1,892 ; \mathrm{Sig}=0,063)$. De acordo com os valores da média dos outros itens, pode-se verificar que os respondentes dão importância à marca de tênis e importam-se em melhorar o desempenho constantemente em corridas. Praticamente não houve 
dificuldades para responder à pesquisa e o grau de envolvimento dos respondentes foi ótimo. Tanto o poder quanto a dependência foram superiores para a marca Asics, demonstrando validade da proposta de manipulação.

A seguir, apresenta-se os resultados da comparação de médias de poder pessoal de acordo com os cenários de marca (Figura 3).

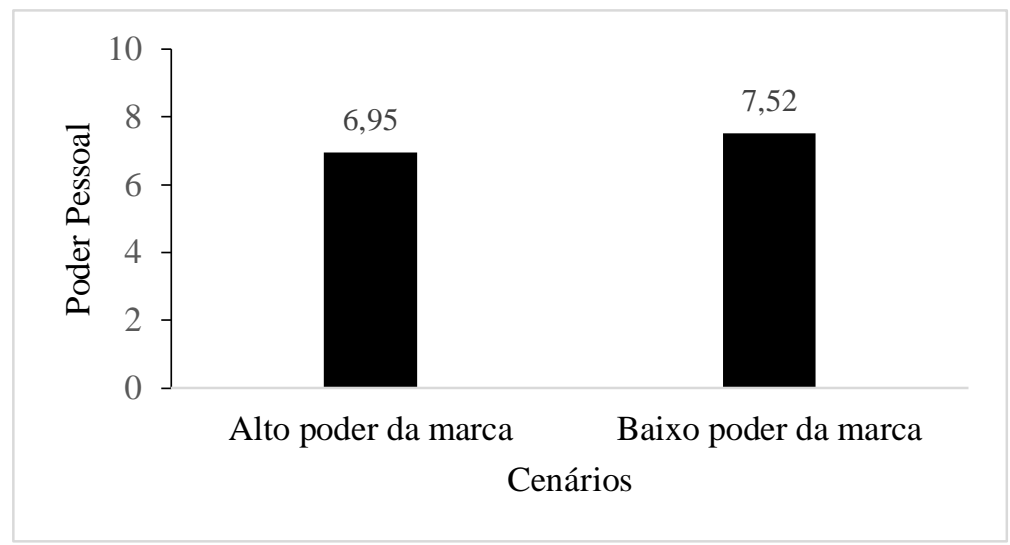

Figura 3. Média do Poder Pessoal por Cenário de Marca (Exp. 2)

t-value: 2,478; $\mathrm{Sig}=0,016$; Alpha de Cronbach: 0,71. Fonte: elaborada pelos autores.

Os resultados da Figura 2 indicam que o senso de poder pessoal é menor quando o indivíduo utiliza marcas com alto poder, neste caso, Asics, do que ao utilizar marcas com baixo poder, Rainha, confirmando novamente a hipótese 1 do estudo.

Por último, testou-se a hipótese 2. O teste de mediação segue os procedimentos indicados por Preacher, Rucker e Hayes (2007), baseando-se no modelo 4 de Hayes (2013), conforme Figura 4.

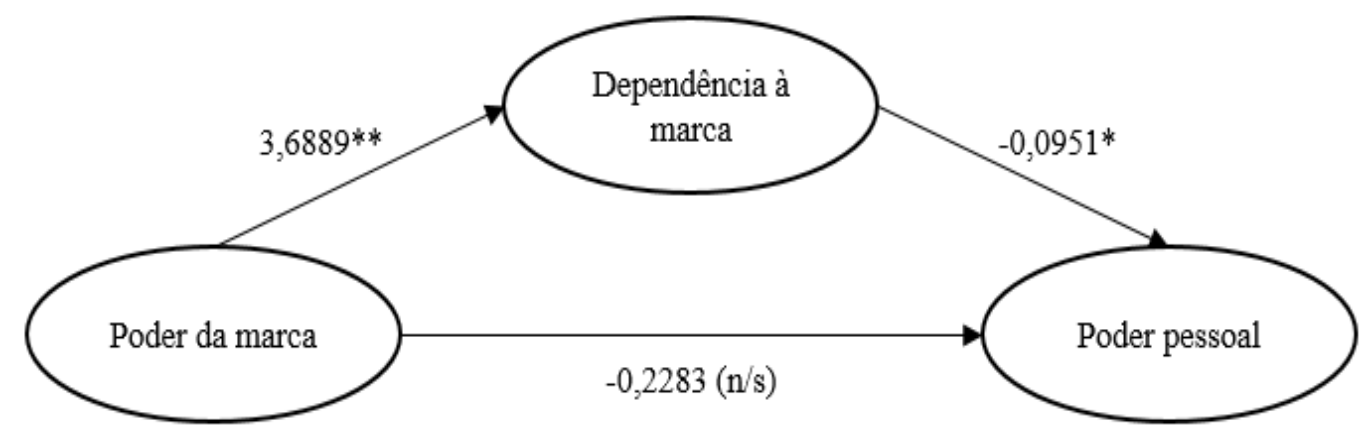

Figura 4. Modelo de Mediação (Dependência) (Exp. 2)

$* \operatorname{Sig}<0,05 ; * * \operatorname{Sig}<0,01 ; R^{2}=0,1472 ; \mathrm{F}(2,57)=4,9207 ; \operatorname{Sig}=0,0107$. Fonte: elaborada pelos autores.

De acordo com os coeficientes não padronizados, observa-se que o poder da marca exerce influência positiva sobre a dependência em relação à marca. $\mathrm{O}$ poder da marca, mediado pela dependência, tem um impacto negativo no poder pessoal. Não há influência direta do poder da marca sobre o poder pessoal, ou seja, há mediação completa no modelo. A seguir, na Tabela 5, apresenta-se o resultado dos efeitos direto, indireto e total do modelo de mediação testado. 
Tabela 5

Poder da Marca e Poder Pessoal Mediado pela Dependência (Exp. 2)

\begin{tabular}{lccccc}
\hline & Efeito & Erro & Sig & IC Inferior & IC Superior \\
\hline Efeito total & $-0,5792$ & 0,2337 & 0,0161 & $-1,0469$ & $-0,1114$ \\
Efeito direto & $-0,2283$ & 0,2970 & 0,4452 & $-0,8230$ & 0,3664 \\
Efeito indireto (dependência) & $-0,3509$ & 0,1935 & & $-0,7845$ & $-0,0125$ \\
\hline
\end{tabular}

Nota. Método de Bootstrap (5.000). Fonte: elaborada pelos autores.

Os resultados demonstram que só há influência do poder da marca sobre o poder pessoal quando mediada pela dependência em relação à marca, ou seja, quando há mediação completa. $\mathrm{O}$ efeito direto do poder da marca sobre o poder pessoal não é significativo. Já o efeito indireto de $-0,3509$ do poder da marca sobre o poder pessoal com a mediação da dependência é significativo. Por ser negativo, o efeito demonstra que há diminuição do poder pessoal quando a percepção de poder da marca é crescente, sendo esta relação verdadeira somente quando mediada pela dependência.

Em síntese, a relação entre poder da marca e poder pessoal pode ser melhor explicada através da mediação da dependência. Tal variável imprime um efeito negativo aumentando a diferença de poder pessoal dos consumidores que utilizam marcas fortes e fracas. Pode-se afirmar que a dependência contribui para a diminuição do poder pessoal na presença de uma marca forte, comparado a uma marca fraca, aumentando a assimetria de poder entre consumidor e marca.

Os resultados do experimento 2 comprovam a segunda hipótese do estudo e corroboram as evidências teóricas apresentadas por outros autores. A dependência de um sujeito é uma fonte potencial de poder para outro (Molm, 1991). Em relações desbalanceadas, A é a parte mais poderosa, pois B é o mais dependente dos dois (Emerson, 1962). O desequilíbrio de poder captura a diferença no poder de cada sujeito em relação ao outro. Formalmente, este construto pode ser definido como a diferença entre a dependência de dois indivíduos ou do nível de poder do mais poderoso em relação ao menos poderoso (Casciaro \& Piskorski, 2005). O desequilíbrio de poder nos relacionamentos advém da assimetria na dependência entre as partes, o que contribui para a diferença de influência (Wolfe \& Mcginn, 2005).

\section{Experimento 3}

O terceiro experimento teve como objetivo reforçar os achados dos experimentos anteriores, testando novamente as hipóteses 1 e 2, além de avaliar uma nova hipótese (H3). O contexto empregado neste estudo foi a avaliação de marcas de notebook (CCE e SONY). Para a avaliação da hipótese 3 houve a manipulação do cenário de confiança (baixa e alta).

A amostra do terceiro experimento foi composta por 133 respondentes, sendo distribuídos randomicamente entre as quatro condições. $O$ design do experimento foi fatorial 2 (poder da marca: alto e baixo) x 2 (confiança: alta e baixa), entre grupos (between subjects). Para a condição de alto poder da marca, foi escolhida a marca SONY e, para a condição de baixo poder da marca, utilizou-se a marca CCE. A escolha baseia-se em um levantamento com 38 indivíduos. A marca Sony foi a mais citada (com 10 votos), seguida da Dell e Apple (com 8 votos cada). A marca HP teve 3 votos e as outras marcas não tiveram mais do que 2 votos.

Os participantes do experimento 3 eram universitários, sendo 56,4\% do sexo feminino. A média de idade foi 23,01 anos (D.P.: 5,06). A aplicação do questionário em papel se deu de forma presencial em salas de aula nos cursos de graduação em administração e marketing de uma universidade privada. A maior parte, $89,4 \%$ para CCE e $65,7 \%$ para SONY, nunca teve um aparelho da marca. Primeiramente, cada indivíduo leu um dos cenários em relação ao poder da marca. 
Tabela 6

\section{Cenários da Marca (Exp.3)}

\begin{tabular}{ll}
\hline Marca com baixo poder & Marca com alto poder \\
\hline $\begin{array}{l}\text { Imagine-se na seguinte situação: Você está em uma } \\
\text { fase crítica da sua vida, final de semestre na faculdade }\end{array}$ & $\begin{array}{l}\text { Imagine-se na seguinte situação: Você está em uma } \\
\text { fase crítica da sua vida, final de semestre na faculdade }\end{array}$ \\
e você precisa realizar diversos trabalhos (TCC, & e você precisa realizar diversos trabalhos (TCC, \\
trabalhos de disciplinas, apresentações). Para isso, & trabalhos de disciplinas, apresentações). Para isso, \\
você acaba de comprar um notebook da marca CCE & você acaba de comprar um notebook da marca SONY \\
com a seguinte configuração: tela de 15 polegadas, & com a seguinte configuração: tela de 15 polegadas, \\
processador com velocidade de 2.90 GHz, 4 gb de & processador com velocidade de 2.90 GHz, 4 gb de \\
memória RAM e 500 gb de HD. A compra deste & memória RAM e 500 gb de HD. A compra deste \\
notebook é muito importante para que você consiga & notebook é muito importante para que você consiga \\
realizar todas as suas tarefas e cumprir o prazo de & realizar todas as suas tarefas e cumprir o prazo de \\
entrega dos trabalhos. Descreva abaixo como você se & entrega dos trabalhos. Descreva abaixo como você se \\
sentiria usando um notebook da marca CCE nesta & sentiria usando um notebook da marca SONY nesta \\
situação. & situação. \\
\hline
\end{tabular}

Nota. Fonte: elaborada pelos autores.

Posteriormente, cada participante leu um dos cenários sobre situações diferentes que manipulavam o nível de confiança na marca. A descrição procurou atender às características da confiança, ou seja, quando o consumidor pode contar com a marca, ele a considera segura e honesta.

Tabela 7

Cenário de Confiança (Exp. 3)

\begin{tabular}{|c|c|}
\hline Baixa Confiança & Alta Confiança \\
\hline $\begin{array}{l}\text { Agora pense novamente na seguinte situação: Após } \\
\text { alguns dias de uso do seu novo notebook SONY/CCE, } \\
\text { ele apresentou sérios problemas. Por um motivo } \\
\text { inexplicável, ele começou a esquentar demais. } \\
\text { Consequentemente, ele parou de funcionar. Neste } \\
\text { momento, você não sabe se conseguirá recuperar seus } \\
\text { arquivos da faculdade. Você contatou o serviço de pós- } \\
\text { venda e garantia da SONY/CCE e eles disseram que } \\
\text { houve um problema de fabricação do lote de } \\
\text { computadores que você comprou e que a marca trocaria } \\
\text { o produto no prazo de } 45 \text { dias. No site Reclame Aqui } \\
\text { existiam milhares de reclamações sobre a marca } \\
\text { SONY/CCE, inclusive sobre o descumprimento do } \\
\text { prazo da troca do produto. O PROCON já havia } \\
\text { entrado com uma ação coletiva contra a marca, mas, até } \\
\text { o momento, nada havia sido determinado pela justiça e } \\
\text { os usuários continuavam com o problema em mãos. } \\
\text { Descreva abaixo como você se sentiria usando um } \\
\text { notebook da marca SONY/CCE nesta situação. }\end{array}$ & $\begin{array}{l}\text { Agora pense novamente na seguinte situação: Após } \\
\text { alguns dias de uso do seu novo notebook SONY/CCE, } \\
\text { ele atendeu a todas as suas expectativas e você } \\
\text { conseguiu realizar todos os trabalhos da faculdade. O } \\
\text { desempenho do produto foi totalmente adequado. No } \\
\text { site Reclame Aqui não há nenhuma reclamação sobre } \\
\text { a marca SONY/CCE, o que comprova que a marca é } \\
\text { altamente confiável e você acertou na escolha da } \\
\text { marca. Descreva abaixo como você se sentiria usando } \\
\text { um notebook da marca SONY/CCE nesta situação. }\end{array}$ \\
\hline
\end{tabular}

Nota. Fonte: elaborada pelos autores.

A seguir, apresenta-se os resultados da checagem dos cenários no experimento 3 (Tabela 8). 
Tabela 8

Checagens do Experimento 3 - Cenário de Marca

\begin{tabular}{lcccccc}
\hline & Cenários & Média & D.P. & t-value & Sig & Alpha \\
\hline Importância da marca & CCE & 5,71 & 2,99 & 0,758 & 0,450 & \\
& SONY & 5,32 & 2,85 & & & \\
\hline Realismo do cenário & CCE & 6,62 & 2,47 & $-2,422$ & 0,017 & \\
& SONY & 7,53 & 1,82 & & & \\
\hline Dificuldade para responder à pesquisa & CCE & 2,65 & 2,53 & $-0,089$ & 0,929 & \\
& SONY & 2,68 & 1,94 & & & \\
\hline Envolvimento com a pesquisa & CCE & 8,42 & 1,69 & 0,188 & 0,851 & \\
& SONY & 8,37 & 1,43 & & & \\
\hline Poder da marca & CCE & 2,37 & 0,95 & $-15,843$ & 0,00 & $>0,8$ \\
& SONY & 5,53 & 1,31 & & & \\
\hline Dependência em ralação à marca & CCE & 2,58 & 1,08 & $-13,066$ & 0,00 & 0,755 \\
& SONY & 5,61 & 1,54 & & & \\
\hline
\end{tabular}

Nota. Fonte: elaborada pelos autores.

Observa-se que os valores estão adequados e não há diferença entre as condições para as variáveis importância da marca, dificuldade para responder à pesquisa e envolvimento com a pesquisa. Já para o realismo do cenário houve diferença entre as condições, sendo considerado o cenário da marca SONY mais real do que o da marca CCE. Os valores referentes às escalas de poder e dependência em relação à marca foram superiores para a marca SONY, conforme esperado. A Tabela 9 demonstra a checagem das variáveis de controle por cenário de confiança.

Tabela 9

Checagens do Experimento 3 - Cenário de Confiança

\begin{tabular}{lcccccc}
\hline & Cenários & Média & $\begin{array}{c}\text { Desvio } \\
\text { Padrão }\end{array}$ & t-value & Sig & Alpha \\
\hline Importância da marca & Baixa confiança & 5,34 & 2,99 & $-0,698$ & 0,486 & \\
& Alta confiança & 5,69 & 2,84 & & & \\
\hline Realismo do cenário & Baixa confiança & 7,68 & 2,09 & 3,282 & 0,001 & \\
& Alta confiança & 6,46 & 2,17 & & & \\
\hline Dificuldade para responder à pesquisa & Baixa confiança & 2,55 & 2,17 & $-0,602$ & 0,548 & \\
& Alta confiança & 2,78 & 2,33 & & & \\
\hline Envolvimento com a pesquisa & Baixa confiança & 8,51 & 1,48 & 0,810 & 0,420 & \\
& Alta confiança & 8,29 & 1,64 & & & \\
\hline Confiança na marca & Baixa confiança & 5,25 & 2,78 & $-1,888$ & 0,06 & 0,964 \\
& Alta confiança & 6,09 & 2,35 & & & \\
\hline
\end{tabular}

Nota. Fonte: elaborada pelos autores. 
Para os cenários de confiança, pode-se verificar que as variáveis de checagens possuem valores adequados, não havendo diferença entre os níveis de confiança, exceto para o realismo do cenário cuja condição de baixa confiança pareceu mais realista do que a condição de alta confiança, porém ambos cenários, neste caso, atingiram um valor de média representativo, indicando o não comprometimento da validade interna do experimento. Os valores das médias de confiança, de acordo com cada cenário, confirmam marginalmente a efetividade das manipulações, já que a diferença atingiu um nível de significância de 0,06 .

Para o teste novamente da H1, apresenta-se, a seguir, os resultados da comparação de médias do poder pessoal em relação a cada cenário de marca, conforme Figura 5.

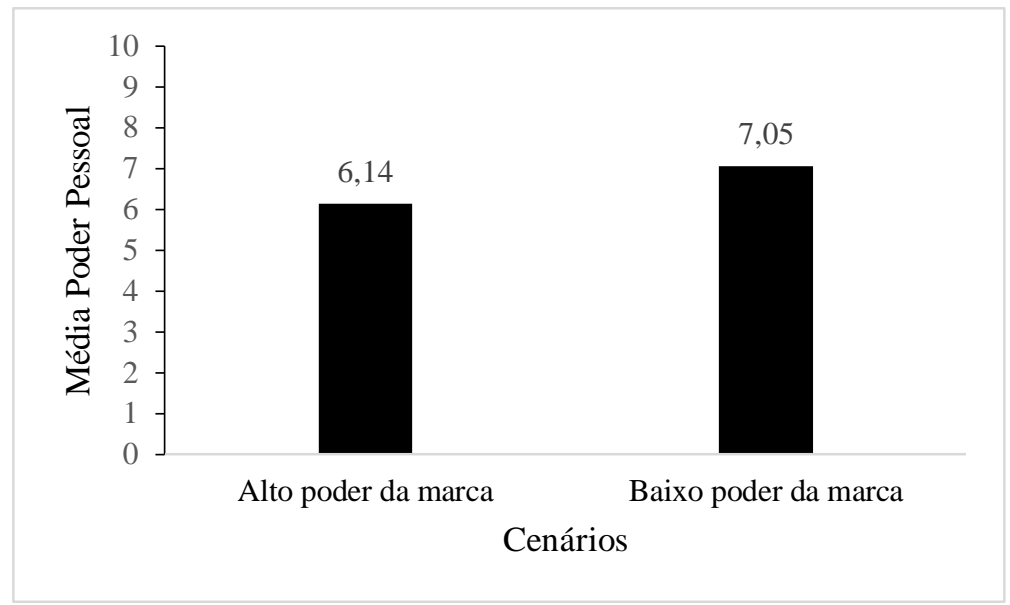

Figura 5. Média do Poder Pessoal por Cenário de Marca (Exp. 3)

t-value: 4,935; Sig= 0,00; Alpha de Cronbach: 0,834. Fonte: elaborada pelos autores.

Conforme esperado, o poder pessoal foi menor na presença da marca SONY (alto poder da marca) do que na condição da marca CCE (baixo poder da marca), confirmando novamente a Hipótese 1 do estudo.

Realizou-se novamente o teste da hipótese 2 através dos procedimentos indicados por Preacher et al. (2007), baseando-se no modelo 4 de Hayes (2013). A mediação da dependência na relação entre poder da marca e poder pessoal foi completa, já que apenas o efeito indireto negativo $($ Efeito $=-0,471)$ foi significativo ( $\mathrm{ICI}=-0,9294 / \mathrm{ICS}=-0,0125)$. Este resultado corrobora novamente a hipótese 2 do estudo e torna-se fundamental para o teste da hipótese 3.

A seguir, apresenta-se os resultados da interação entre o poder da marca e a confiança em relação ao senso de poder pessoal (Figura 6). 


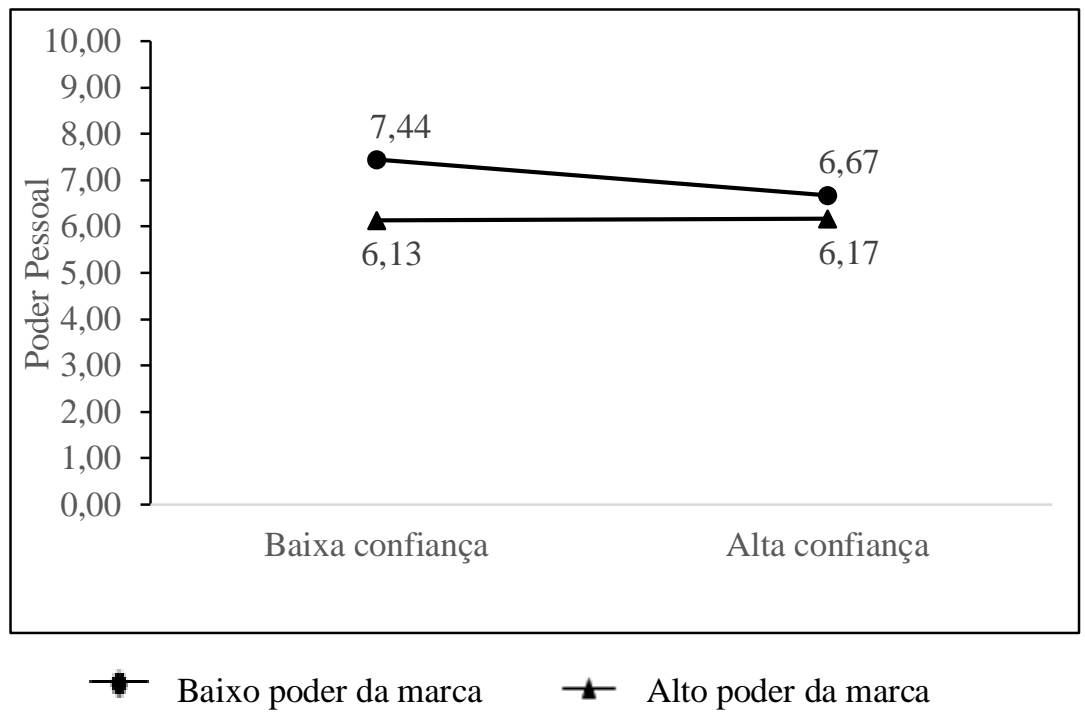

Figura 6. Interação entre Poder Pessoal e Poder da Marca nas Condições de Alta e Baixa Confiança Fonte: elaborada pelos autores.

Observa-se, na Figura 2, que o senso de poder pessoal mais elevado se dá na condição de baixa confiança e baixo poder da marca. Nas demais condições, o senso é inferior e não há diferença de média estatisticamente significativa. A interação entre a marca e a confiança foi significativa $(\mathrm{F}=5,218$; $\left.\mathrm{Sig}=0,024 ; \eta^{2}=0,039\right)$. Apenas o efeito direto da marca $\left(\mathrm{F}=25,680 ; \mathrm{Sig}=0,00 ; \eta^{2}=0,166\right)$ foi superior à interação. $\mathrm{O}$ efeito da confiança $\left(\mathrm{F}=4,120 ; \mathrm{Sig}=0,044 ; \eta^{2}=0,031\right)$ foi inferior à interação. A assimetria de poder será maior para o cenário de baixa confiança na marca. Pode-se inferir que a confiança age como um mecanismo na diminuição da assimetria. Tal inferência será adiante testada pelo modelo de mediação moderada.

Por último, apresenta-se os resultados da relação entre poder da marca e poder pessoal mediada pela dependência e moderada pela confiança. A moderação se dá na relação entre poder da marca e dependência. Este teste segue a proposta apresentada por Preacher et al. (2007), baseando-se no modelo 7 de Hayes (2013). Primeiramente, apresenta-se o gráfico do modelo com índices de coeficientes não padronizados e os valores de significância.

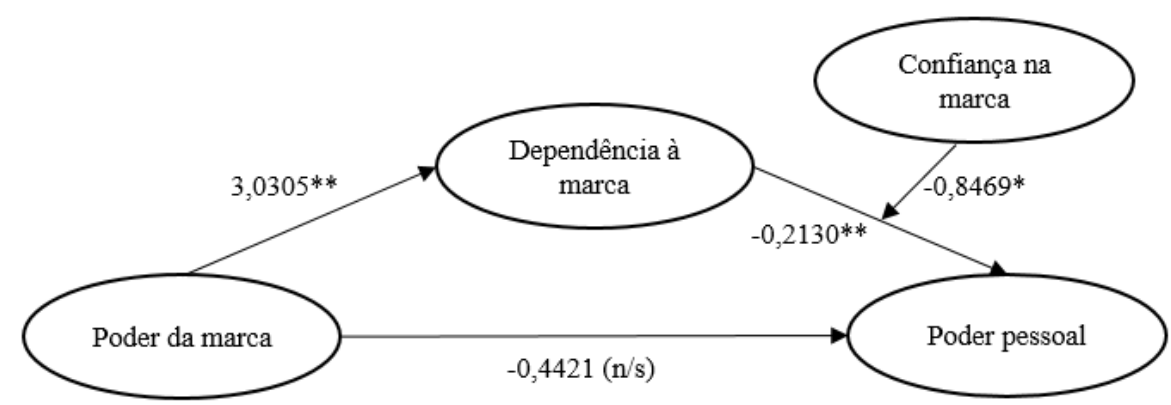

Figura 7. Modelo de Mediação (Dependência) Moderada (Confiança) (Exp. 3) $* \operatorname{Sig}<0,05 ; * * \operatorname{Sig}<0,01 \mathrm{R}^{2}=0,2194 ; \mathrm{Sig}=0,00$. Fonte: elaborada pelos autores.

De acordo com os coeficientes não padronizados, pode-se observar que há influência positiva do poder da marca sobre a dependência e influência negativa do poder da marca, mediado pela dependência, sobre o poder pessoal. Não há influência direta do poder da marca sobre o poder pessoal. Na moderação total da confiança, o coeficiente não padronizado também foi negativo. $O$ coeficiente de determinação $\left(\mathrm{R}^{2}\right)$ alcançou o valor de 0,2194 (Sig=0,00). Estes resultados demonstram que, de fato, a dependência exerce função de mediação, e a confiança, de moderação, sendo negativos tais efeitos indiretos. Para melhor compreensão dos resultados do modelo, apresenta-se a seguir os valores dos efeitos direto e indireto. 
Tabela 10

Poder da Marca e Poder Pessoal Mediado pela Dependência e Moderado pela Confiança

\begin{tabular}{lccccc}
\hline & $\begin{array}{c}\text { Moderação } \\
\text { Confiança }\end{array}$ & Efeito & Erro & $\begin{array}{c}\text { IC } \\
\text { Inferior }\end{array}$ & $\begin{array}{c}\text { IC } \\
\text { Superior }\end{array}$ \\
\hline Efeito direto & & $-0,4421$ & 0,2749 & $-0,9862$ & 0,1019 \\
Efeito indireto (mediador dependência) & Baixa & $-0,6456$ & 0,2803 & $-1,2160$ & $-0,1162$ \\
& Alta & $-0,2388$ & 0,2684 & $-0,7659$ & 0,2910 \\
\hline
\end{tabular}

Nota. Método de Bootstrap (5.000). Fonte: elaborada pelos autores.

$\mathbf{R}^{2}=0,2194$ (Sig=0,00). Interação do poder da marca e confiança $=$ Sig 0,1368.

Os resultados confirmam a hipótese 3 , que defende o papel moderador da confiança na relação de mediação da dependência entre o poder da marca e o poder pessoal. $\mathrm{O}$ efeito direto não foi significativo, configurando-se em mediação moderada completa. O efeito negativo da mediação foi mais intenso na condição de baixa confiança do que na condição de alta confiança.

No experimento 3, novamente a primeira hipótese do estudo foi comprovada. Os participantes que foram expostos ao cenário da marca forte tiveram uma média de poder pessoal significativamente menor do que aqueles apresentados à marca fraca. A hipótese 2 também foi novamente comprovada, já que a mediação da dependência na relação entre poder da marca e poder pessoal foi completa com um efeito negativo significante. A última hipótese do estudo (H3) também foi confirmada. O efeito direto não foi significativo, configurando-se em mediação moderada completa. O efeito negativo da mediação foi significativo apenas na condição de baixa confiança, demonstrando que o efeito indireto negativo do poder da marca sobre o poder pessoal, mediado pela dependência, não ocorre quando há alta confiança na marca.

Os resultados do experimento 3 corroboram a terceira hipótese do estudo e confirmam as evidências teóricas apresentadas por outros autores. Para Rousseau et al. (1998), a confiança possui um importante papel moderador nas relações teóricas em que prevalece condições de causalidade entre construtos, principalmente nos estudos sobre comportamentos interpessoais. Singh e Sirdeshmukh (2000) expõem claramente que os estados de confiança e falta de confiança são qualitativamente diferentes em termos de valência (positiva e negativa) e têm um potencial impacto sobre a igualdade ou assimetria da relação. Algumas díades possuem igualdade de poder, outras, desigualdade. A principal expectativa é que o nível de confiança seja mais alto em grupos onde a díade tenha simetria de poder do que quando há assimetria de poder (Öberg \& Svensson, 2010). Para ambas as partes (alta e baixa dependência), níveis de alta confiança reduzem o impacto da assimetria na interdependência (Geyskens, Steenkamp, Scheer, \& Kumar, 1996). Quando há alta dependência e baixa confiança, a intenção de cooperação é baixa, aumentando, assim, a assimetria entre as partes (Andaleeb, 1995). Relacionamentos com alta interdependência exibem alta confiança, forte comprometimento e baixo nível de conflitos. Relacionamentos assimétricos em relação à dependência e poder são mais disfuncionais, menos estáveis e há menor confiança recíproca entre os parceiros do que em relacionamentos simétricos. A confiança emerge quando há convergência bilateral, dependência mútua, entre os parceiros (Kumar et al., 1995).

\section{Discussão geral dos resultados}

O primeiro experimento tratou de evidenciar a relação direta entre poder da marca e o poder pessoal. $\mathrm{O}$ achado mais relevante foi a evidência da assimetria de poder existente na relação entre consumidores e marcas, sendo que consumidores se sentem mais poderosos na presença de uma marca fraca e com menos poder quando estão frente a uma marca com alto poder. Este resultado apoia-se nas teorias sobre poder e dominância que argumentam que o poder é inerente a toda relação social e, por consequência, haverá sempre uma parte dominante com mais poder e outra submissa com menos poder. Tal descoberta foi fundamental para a continuidade da investigação do fenômeno nos experimentos 
subsequentes, que buscaram entender os mecanismos explicativos e condicionais da assimetria de poder entre consumidor e marca.

O experimento 2 procurou reforçar a validação da primeira hipótese corroborada no primeiro experimento e, ainda, testar a segunda hipótese, que trata do papel mediador da dependência na relação entre poder da marca e poder pessoal. A formulação desta hipótese baseia-se nas teorias sobre poder e dependência, que defendem que a dependência de uma das partes é a fonte de poder para a outra, ou seja, quanto maior a dependência do consumidor em relação à marca, menor o seu poder na relação. $\mathrm{O}$ segundo experimento provou que este fato é verdadeiro ao testar o modelo mediado e indicando que a dependência exerce mediação completa na relação entre poder da marca e poder pessoal, sendo o efeito negativo e significativo. Este achado foi fundamental para explicar como a assimetria de poder ocorre na relação entre marca e consumidor, ou seja, a dependência é um mecanismo do aumento da desigualdade de poder no relacionamento.

O terceiro experimento se propôs a avançar na explicação do fenômeno em discussão e buscou testar novamente as hipóteses 1 e 2 e, além disso, apresentar em que condição o efeito mediado da dependência na relação entre poder da marca e poder pessoal é mais intenso (H3). Assim, a variável moderadora escolhida foi a confiança. Esta escolha parte da premissa teórica que a confiança exerce um papel fundamental no fortalecimento do relacionamento, atuando como um mecanismo de diminuição da assimetria de poder entre os parceiros. Desta maneira, testou-se novamente o modelo de mediação da dependência na relação entre poder da marca e poder pessoal, porém agora sob a moderação de dois níveis manipulados de confiança. Os resultados apontam que, de fato, na condição de alta confiança, a assimetria de poder entre consumidor e marca é menor do que no nível de baixa confiança, pois a diferença significativa entre as médias do poder pessoal para marcas com alto e baixo poder é evidente apenas na situação de baixa confiança. Além disso, o efeito do poder da marca sobre o poder pessoal, mediado pela dependência, é significativo apenas para a condição moderada de baixa confiança. Este achado corrobora a terceira hipótese do estudo e proporciona um entendimento mais completo de como e quando a relação de poder entre marca e consumidor é mais assimétrica.

\section{Considerações Finais}

Uma das contribuições teóricas deste estudo foi apresentar um modelo de pesquisa inédito com variáveis nunca antes relacionadas. Algumas destas variáveis foram timidamente exploradas isoladamente, como é o caso do poder da marca e o poder pessoal. Toda a relação entre as variáveis testadas no modelo de pesquisa deste estudo traz uma grande contribuição teórica para a área de marketing e comportamento do consumidor, inaugurando novas reflexões acerca do papel do poder no relacionamento entre consumidor e marca.

Além de contribuições para a teoria, este trabalho também visou prover gestores de marketing sobre novas possibilidades para a criação de estratégias que possam ser viáveis e benéficas para as marcas e consumidores.

Diversas limitações metodológicas e empíricas estiveram presentes neste estudo. Primeiramente, um fator que não foi totalmente controlado é a experiência prévia dos consumidores com as marcas, trazendo, assim, atitudes positivas ou negativas no julgamento do poder, dependência e confiança em relação às marcas. Outra limitação encontra-se nos procedimentos de coleta de dados. Os experimentos 1 e 3 foram coletados em sala de aula com estudantes universitários. Uma limitação mais estrutural do trabalho se refere à percepção de realismo dos cenários.

Sugere-se estudos futuros que possam corrigir as imperfeições da atual pesquisa. Futuros trabalhos poderão verificar quais são os fatores antecedentes que contribuem para o aumento ou a diminuição do poder de uma marca. Assim, outras variáveis independentes - propositalmente omitidas neste estudo para que o objetivo fosse atendido - poderiam ser testadas, como brand equity, que expressa 
a força da marca através da resposta positiva e diferenciada do consumidor baseado no conhecimento que este possui sobre a marca (Keller \& Machado, 2006). O estudo das consequências da assimetria de poder entre consumidor e marca também seria um caminho válido a se percorrer. Novas descobertas de outras possíveis variáveis de mediação e moderação que enriqueçam o modelo de pesquisa atual e tragam novas vias de explicação para o fenômeno também são pertinentes.

\section{Referências}

Ailawadi, K. L. (2001). The retail power-performance conundrum: what have we learned?. Journal of Retailing, 77(3), 299-318. doi: 10.1016/S0022-4359(01)00047-1

Andaleeb, S. S. (1995). Dependence relations and the moderating role of trust: implications for behavioral intentions in marketing channels. International Journal of Research in Marketing, 12(2), 157-172. doi: 10.1016/0167-8116(94)00020-O

Anderson, C., John, O. P., \& Keltner, D. (2012). The personal sense of power. Journal of Personality, 80(2), 313-344. doi: 10.1111/j.1467-6494.2011.00734.x

Anderson, J. C., \& Gerbing, D. W. (1988). Structural equation modeling in practice: a review and recommended two-step approach. Psychological Bulletin, 103(3), 411-423. doi: 10.1037/00332909.103.3.411

Bagozzi, R. P., \& Edwards, J. R. (1998). A general approach for representing constructs in organizational research. Organizational Research Methods, 1(1), 45-87. doi: 10.1177109442819800100104

Baldwin, D. A. (1978). Power and social exchange. The American Political Science Review, 72, 12291242. doi: $10.2307 / 1954536$

Belk, R. W. (1988). Possessions and the extend self. Journal of Consumer Research, 15(2), 139-168. doi: $10.1086 / 209154$

Blomqvist, K. (1997). The many faces of trust. Scandinavian Journal of Management, 13(3), 271-286. doi: 10.1016/S0956-5221(97)84644-1

Bunker, M., \& Ball, A. D. (2009). Consequences of customer powerlessness: secondary control. Journal of Consumer Behaviour, 8(5), 268-283. doi: 10.1002/cb.287

Burt, S. L., \& Sparks, L. (2003). Power and competition in the UK retail grocery market. British Journal of Management, 14(3), 237-254. doi: 10.1111/1467-8551.00377

Cai, S., Goh, M., Souza, R. de, \& Li, G. (2013). Knowledge sharing in collaborative supply chains: twin effects of trust and power. International Journal of Production Research, 51(7), 2060-2076. doi: $10.1080 / 00207543.2012 .701780$

Casciaro, T., \& Piskorski, M. J. (2005). Power imbalance, mutual dependence, and constraint absorption: a closer look at resource dependence theory. Administrative Science Quarterly, 50(2), 167-199. doi: 10.2189/asqu.2005.50.2.167

Chaudhuri, A., \& Holbrook, M. B. (2001). The chain of effects from brand trust and brand affect to brand performance: the role of brand loyalty. Journal of Marketing, 65(2), 81-93. doi: 10.1509/jmkg.65.2.81.18255 
Crosno, J. L., Freling, T. H., \& Skinner, S. J. (2009). Does brand social power mean market might? Exploring the influence of brand social power on brand evaluations. Psychology \& Marketing, 26(2), 91-121. doi: 10.1002/mar.20263

Dunbar, N. E. (2000). Explication and initial test of dyadic power theory (Doctoral dissertation). Department of Communication, University of Arizona, Tucson, Arizona, USA.

Emerson, R. M. (1962). Power-dependence relations. American Sociological Review, 27(1), 31-41. doi: $10.2307 / 2089716$

Fiske, S. T., \& Berdahl, J. (2007). Social power. In A. W. Kruglanski \& E. T. Higgins (Eds.), Social psychology: handbook of basic principles (pp. 68-692). New York: Guilford Press.

Fournier, S. (1998). Consumers and their brands: developing relationship theory in consumer research. Journal of Consumer Research, 24(4), 343-353. doi: 10.1086/209515

Fournier, S., \& Alvarez, C. (2013). Relating badly to brands. Journal of Consumer Psychology, 23(2), 253-264. doi: 10.1016/j.jpps.2013.01.004

Francisco-Maffezzolli, E. C., Semprebon, E., \& Prado, P. H. M. (2014). Construing loyalty through brand experience: the mediating role of brand relationship quality. Journal of Brand Management, 21(5), 446-458. doi: 10.1057/bm.2014.16

French, J. R., Jr. (1956). A formal theory of social power. Psychological Review, 63(3), 181-194. doi: $10.1037 / \mathrm{h} 0046123$

Friedmann, J. (1992). Empowerment: the politics of alternative development. Oxford: Blackwell.

Fuchs, D., \& Kalfagianni, A. (2009). Discursive power as a source of legitimation in food retail governance. The International Review of Retail, Distribution and Consumer Research, 19(5), 553-570. doi: 10.1080/09593960903445434

Galinsky, A. D., Gruenfeld, D. H., \& Magee, J. C. (2003). From power to action. Journal of Personality and Social Psychology, 85(3), 453-466. doi: 10.1037/0022-3514.85.3.453

Geyskens, I., Steenkamp, J. B. E., Scheer, L. K., \& Kumar, N. (1996). The effects of trust and interdependence on relationship commitment: a trans-Atlantic study. International Journal of Research in Marketing, 13(4), 303-317. doi: 10.1016/S0167-8116(96)0006-7

Goodwin, C. J. (2007). Research in psychology: methods and design. New Jersey: John Wiley \& Sons.

Grimes, A. J. (1978). Authority, power, influence and social control: a theoretical synthesis. Academy of Management Review, 3(4), 724-735. doi: 10.5465/AMR.1978.4289263

Hair, J. F., Jr., Anderson, R. E., Tatham, R. L., \& Black, W. C. (2005). Análise multivariada de dados (5a ed.). Porto Alegre: Bookman.

Hanzaee, K. H., Ghalandri, K., \& Norouzi, A. (2011). The effect of brand social power dimensions on purchasing decision based on iranian customers' subjective readiness. World Applied Sciences Journal, 13(5), 1197-1208.

Hayes, A. F. (2013). Model templates for SPSS and SAS. Retrieved from http://afhayes.com/public/templates.pdf

Inderst, R., \& Shaffer, G. (2007). Retail mergers, buyer power and product variety. The Economic Journal, 117(516), 45-67. doi: 10.1111/j.1468-0297.2007.02001.x 
Jarvis, C. B., MacKenzie, S. B., \& Podsakoff, P. M. (2003). A critical review of construct indicators and measurement model misspecification in marketing and consumer research. Journal of Consumer Research, 30(2), 199-218. doi: 10.1086/376806

Jiang, Y., Zhang, L., \& Rucker, D. D. (2012). The power switch: how psychological power influences brand switching decisions. Advances in Consumer Research, 40, 304-305.

Jiang, Y., Zhang, L., \& Rucker, D. D. (2014). Power and action orientation: power as a catalyst for consumer switching behavior. Journal of Consumer Research, 41(1), 183-196. doi: $10.1086 / 675723$

Jin, L., He, Y., \& Zhang, Y. (2014). How power states influence consumers' perceptions of price unfairness. Journal of Consumer Research, 40(5), 818-833. doi: 10.1086/673193

Keller, K. L., \& Machado, M. (2006). Gestão estratégica de marcas. São Paulo: Pearson Prentice Hall.

Keltner, D., Van Kleef, G. A., Chen, S., \& Kraus, M. W. (2008). A reciprocal influence model of social power: emerging principles and lines of inquiry. Advances in Experimental Social Psychology, 40, 151-192. doi: 10.1016/S0065-2601(07)00003-2

Kumar, N., Scheer, L. K., \& Steenkamp, J. B. E. (1995). The effects of perceived interdependence on dealer attitudes. Journal of Marketing Research, 32(3), 348-356. doi: 10.2307/3151986

Laaksonen, T., Pajunen, K., \& Kulmala, H. I. (2008). Co-evolution of trust and dependence in customersupplier relationships. Industrial Marketing Management, 37(8), 910-920. doi: 10.1016/j.indmarman.2007.06.007

Lammers, J., Stoker, J. I., \& Stapel, D. A. (2009). Differentiating social and personal power: opposite effects on stereotyping, but parallel effects on behavioral approach tendencies. Psychological Science, 20(12), 1543-1548. doi: 10.1111/j.1467-9280.2009.02479.x

Lattin, J., Carroll, J. D., \& Green, P. E. (2011). Análise de dados multivariados. São Paulo: Cengage Learning.

Lawler, E. J. (1992). Power processes in bargaining. The Sociological Quarterly, 33(1), 17-34. doi: $10.1111 / \mathrm{j} .1533-8525.1992 . t b 00361 . x$

Malkoc, S. A. (2012). Power and decision making: exploring the processes and nuances. Advances in Consumer Research, 40, 303-307.

Malkoc, S. A., \& Duguid, M. M. (2012). Not all power is created equal: role of social and personal power in decision making. Advances in Consumer Research, 40, 305-306.

McDonald, G. W. (1980). Family power: the assessment of a decade of theory and research, 1970-1979. Journal of Marriage and the Family, 42(4), 841-854. doi: 10.2307/351828

Molm, L. D. (1991). Affect and social exchange: satisfaction in power-dependence relations. American Sociological Review, 56(4), 475-493. doi: 10.2307/2096269

Molm, L. D., \& Cook, K. S. (1995). Social exchange and exchange networks. Sociological Perspectives on Social Psychology, 2, 209-235.

Öberg, P., \& Svensson, T. (2010). Does power drive out trust? Relations between labour market actors in Sweden. Political Studies, 58(1), 143-166. doi: 10.1111/j.1467-9248.2008.00772.x

Olekalns, M., \& Smith, P. (2006, July). Trust, power (A)symmetry and misrepresentation in negotiation. Proceedings of the Annual Conference of International Association for Conflict Management, Montreal, Canada, 19. 
Podsakoff, P. M., MacKenzie, S. B., Lee, J. Y., \& Podsakoff, N. P. (2003). Common method biases in behavioral research: a critical review of the literature and recommended remedies. Journal of Applied Psychology, 88(5), 879-903. doi: 10.1037/0021-9010.88.5.879

Preacher, K. J., Rucker, D. D., \& Hayes, A. F. (2007). Addressing moderated mediation hypotheses: theory, methods, and prescriptions. Multivariate Behavioral Research, 42(1), 185-227. doi: $10.1080 / 00273170701341316$

Rindt, J., \& Mouzas, S. (2015). Exercising power in asymmetric relationships: the use of private rules. Industrial Marketing Management, 48, 202-213. doi: 10.1016/j.indmarman.2015.03.018

Rollins, B. C., \& Bahr, S. J. (1976). A theory of power relationships in marriage. Journal of Marriage and the Family, 38(4), 619-627. doi: 10.2307/350682

Rousseau, D. M., Sitkin, S. B., Burt, R. S., \& Camerer, C. (1998). Not so different after all: a crossdiscipline view of trust. Academy of Management Review, 23(3), 393-404. doi: 10.5465/AMR.1998.926617

Rucker, D. D., Dubois, D., \& Galinsky, A. D. (2011). Generous paupers and stingy princes: power drives consumer spending on self versus others. Journal of Consumer Research, 37(6), 1015-1029. doi: $10.1086 / 657162$

Rucker, D. D., \& Galinsky, A. (2008). The role of power in consumer spending. Advances in Consumer Research, 35, 194-195.

Russell, B. (1938). Power: a new social analysis. New York: W. W. Norton.

Shadish, W. R., Cook, T. D., \& Campbell, D. T. (2002). Experimental and quasi-experimental designs for generalized causal inference. Boston: Houghton Mifflin.

Singh, J., \& Sirdeshmukh, D. (2000). Agency and trust mechanisms in consumer satisfaction and loyalty judgments. Journal of the Academy of Marketing Science, 28(1), 150-167. doi: $10.1177 / 0092070300281014$

Skinner, S. J., Dubinsky, A. J., \& Donnelly, J. H., Jr. (1984). The use of social bases of power in retail sales. Journal of Personal Selling \& Sales Management, 4(2), 48-56. doi: 10.1080/08853134.1984.10754380

Smith, P. K., \& Galinsky, A. D. (2010). The nonconscious nature of power: cues and consequences. Social and Personality Psychology Compass, 4(10), 918-938. doi: 10.1111/j.17519004.2010.00300.x

Thibaut, J. W., \& Kelley, H. H. (1959). Handbook of personal relationships (2nd ed.). New York: John Wiley \& Sons.

Thomson, M., Maclnnis, D. J., \& Park, C. W. (2005). The ties that bind: measuring the strength of consumers' emotional attachments to brands. Journal of Consumer Psychology, 15(1), 77-91. doi: 10.1207/s15327663jcp1501_10

Wolfe, R. J., \& McGinn, K. L. (2005). Perceived relative power and its influence on negotiations. Group Decision and Negotiation, 14(1), 3-20. doi: 10.1007/s10726-005-3873-8

Yani-de-Soriano, M. M., \& Foxall, G. R. (2006). The emotional power of place: the fall and rise of dominance in retail research. Journal of Retailing and Consumer Services, 13(6), 403-416. doi: 10.1016/j.jretconser.2006.02.007 


\section{Dados dos Autores}

Elder Semprebon

Av. Lothario Meissner, 632, 80210-170, Curitiba, PR, Brasil. E-mail: elder.semprebon@ gmail.com

Paulo Henrique Muller Prado

Av. Lothario Meissner, 632, 80210-170, Curitiba, PR, Brasil. E-mail: pprado@ufpr.br 